\title{
IMPACTS OF THE GRAIN FOR GREEN PROJECT ON SOIL EROSION: A CASE STUDY IN THE WUDING RIVER AND LUOHE RIVER BASINS IN THE SHAANXI PROVINCE OF CHINA
}

\author{
WANG, T. ${ }^{1,2}$ \\ ${ }^{1}$ College of Geomatics, Xi'an University of Science and Technology \\ 58 Yanta Road, Xi'an, Shaanxi, P. R. China \\ (e-mail: wht432@xust.edu.cn; phone: +86-29-8912-7648; fax: +86-29-8558-3176) \\ ${ }^{2}$ State Key Laboratory of Soil Erosion and Dryland Farming on the Loess Plateau, Institute of \\ Water and Soil Conservation, Chinese Academy of Sciences and Ministry of Water Resources \\ 26 Xinong Road, Yangling, Shaanxi, P. R. China \\ (phone: +86-29-8701-2411; fax: +86-29-8701-2210) \\ (Received $2^{\text {nd }}$ Apr 2018; accepted $12^{\text {th }}$ Jun 2018)
}

\begin{abstract}
The Loess Plateau in the northern Shaanxi Province is one of the areas with serious soil erosion in China. Affected by the implementation of the Grain for Green project, land use types and vegetation status have changed considerably. To assess the impacts of these changes on soil erosion has important theoretical and practical significance. Taking the Wuding River Basin and Luohe River Basin in northern Shaanxi as examples, land use data, normalized difference vegetation index, and daily rainfall data, as well as digital elevation model, soil type data, combined with the revised universal soil loss equation, the change of the soil erosion modulus were analyzed. The results showed that: (1) the implementation of the Grain for Green project has promoted the conversion of farmland to grassland and forest land (concentrated in 2000-2005). In 2000-2014, the change rate of land use and NDVI in the areas with a slope $\geq 25^{\circ}$ were higher than those areas with a slope $<25^{\circ}$ and across the entire basin. Affected by this, the change rate of the soil erosion modulus difference value at areas with a slope $\geq 25^{\circ}$ was higher than that at areas with a slope $<25^{\circ}$. (2) The soil erosion modulus of both basins increased from 2000 to 2014. Without considering the impact of changed precipitation, the soil erosion modulus of both basins showed a decreasing. This proves that the implementation of the GGP, converting farmland into forest land and grassland, has improved the vegetation coverage and reduced soil erosion.
\end{abstract}

Keywords: RUSLE, rainfall, vegetation, slope, northern Shaanxi Province

\section{Introduction}

Soil erosion is a worldwide eco-environmental problem and has a close relationship with agricultural production (Montgomery, 2007). As one of the main soil erosion regions in China and the world, the Loess Plateau is affected by the terrain, soil, precipitation, surface vegetation cover, and human activities. To reduce soil erosion, the Chinese government has formulated and implemented the Grain for Green project (GGP), which aims to reduce the soil erosion via improving the vegetation cover. Combined with the check-dam project built in the 1970s, soil erosion on the Loess Plateau will be comprehensively managed.

The GGP is an important environmental construction and restoration project in China and involves 1,897 administrative units at the national level, in 25 provinces and autonomous regions across the country. The Loess Plateau is a key area for implementing the GGP and has drawn considerable attention from scholars (Sun et al., 2013; Jiao et al., 2014). Soil erosion has been studied from the micro-slope scale to the whole Loess Plateau, and slope soil erosion research discussed the effects of land use change on soil surface roughness, soil organic matter, and slope micro-topography 
evolution on soil erosion (Hu et al., 2014; Liu et al., 2014; Li et al., 2015, 2017). Studies on channel soil erosion focus on the role of the check-dam construction in the ecological environment as well as socio-economic, water, and sediment reduction effects in the basin (Wang et al., 2014a; Feng et al., 2016; Zhao et al., 2017). Soil erosion in small watersheds has been studied, as well as the effects of land cover change on soil erosion and ecological and economic sustainability (Zhao et al., 2014; Zhang et al., 2016; Dong et al., 2017). The change of soil erosion in the basins before and after the implementation of the GGP also has been analyzed (Wang et al., 2014b; Liu et al., 2015; Li et al., 2016). Overall, studies on the Loess Plateau focus on climate change, vegetation change, and soil erosion change scenarios, with potential governance prospects (Gao et al., 2016; Xie et al., 2016; Gao et al., 2017; Jiang et al., 2018).

At the core area of the Loess Plateau in northern Shaanxi, a hilly-gully area, the implementation of the GGP has played an important role in the improvement of the regional ecological environment. The impact of GGP implementation on soil erosion is the key evaluation content, with a large number of reports. However, comparative analyses of multiple basins are scarce. The Wuding River and the Luohe River are the major rivers on the Loess Plateau in northern Shaanxi. Solid knowledge on the impacts of the GGP on different basins in terms of soil erosion would be used for assess the effectiveness and direction of future implementations.

\section{Materials and methods}

\section{Study sites}

The Wuding River Basin (WDRB) and Luohe River Basin (LHRB) were selected as study sites (Fig. 1). The two basins are located in the areas Yulin and Yan'an, on the Loess Plateau, in the northern part of the province Shaanxi, China (LPNSC). The area is the core area of the Loess Plateau, with a complex topography and severe soil erosion. The dominant vegetation types are temperate forest, temperate grassland, and temperate desert, from south to north. Due to the long history of human activities, the surface in other regions is dominated by artificial vegetation, except for the forest vegetation in the south. The climate is characterized as temperate continental monsoon climate, with hot and rainy summers and cold and dry winters. The inherent characteristics of loess and the undulating surface conditions, as well as the concentrated precipitation in summer and autumn, lead to serious soil erosion in the region.

The Wuding River is the first tributary of the Yellow River. It is located in the northern part of the LPNSC and is mainly distributed in the territory of Yulin. The northwestern part of the basin is flat and sandy and belongs to the southern margin of the $\mathrm{Mu}$ Us Desert, while the southwestern part contains the source of the Wuding River and has a higher elevation; similar to the southeastern part, it is a hilly-gully region. The WDRB is the key basin for soil erosion control on the Loess Plateau. Since the 1970s, more than 10,000 check dams have been built in the basin, with the aim to treat channel soil erosion. Slope vegetation restoration and construction approaches have been adopted since 1999. Large areas of sloping farmland have been turned into forest land and grassland via the GGP implementation, with major land use changes, resulting in improved slope vegetation coverage and increased ecological value; in addition, annual runoff and sediment erosion also decreased.

The Luohe River is mainly located in the area around Yan'an, in the southern part of the LPNSC. It flows into the Weihe River and is a secondary tributary of the Yellow 
River. The vegetation cover in the LHRB is high, and temperate steppe and forest areas are distributed in the northwestern and southern regions of the basin, respectively. As a consequence of GGP implementation, land use in the basin has undergone considerable changes. Compared with the Yanhe River Basin, which is also located in the LPNSC, studies on the Wuding River and the Luohe River are scarce. This paper, therefore, focused on the WDRB and LHRB, analyzing temporal and spatial changes in soil erosion with the implementation of the GGP.

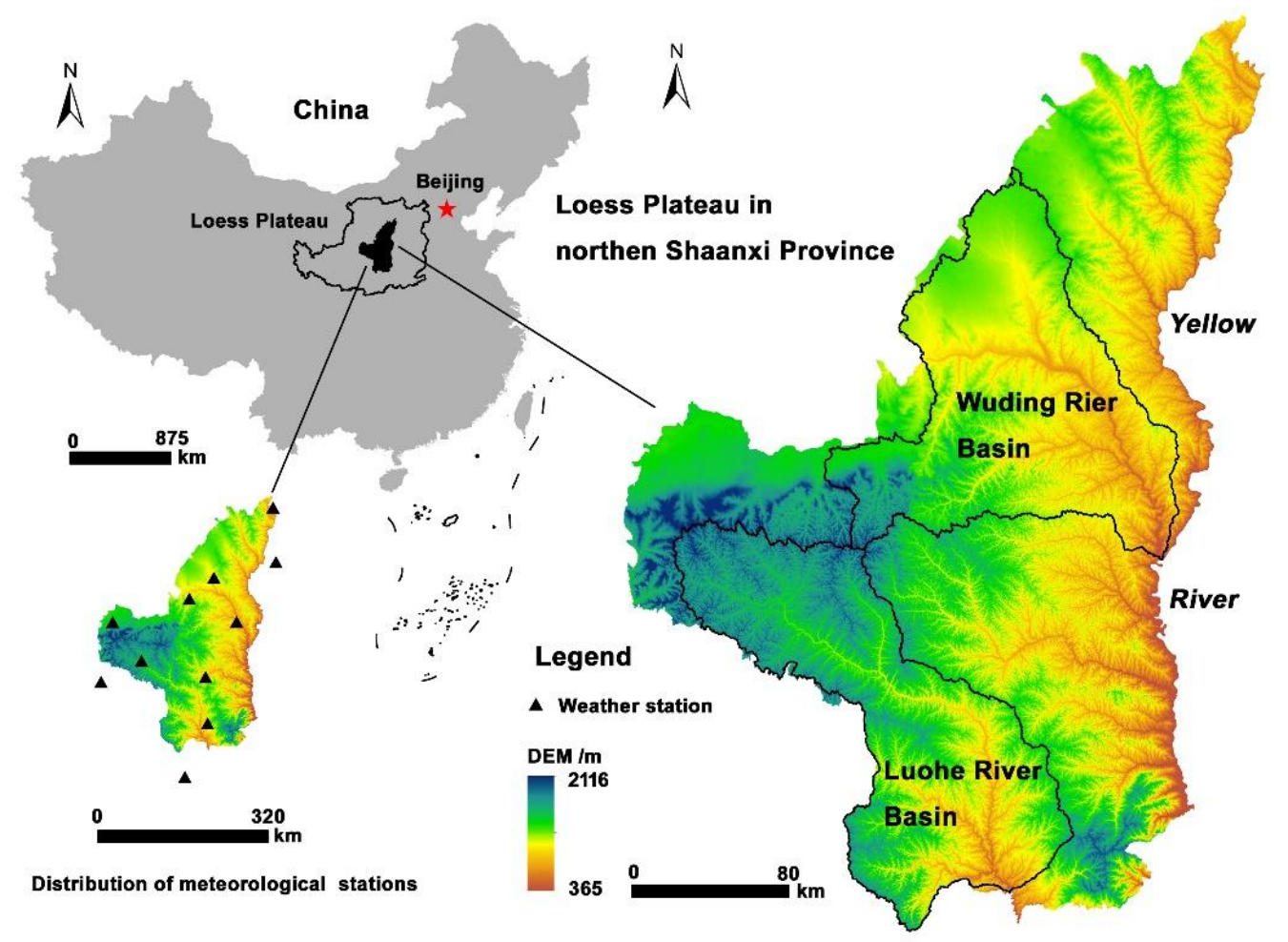

Figure 1. Study sites and the distribution of meteorological stations

\section{Data}

The research data included the following: (1) daily rainfall data, obtained from 11 meteorological stations in and around the basin from 2000 to 2014 (Fig. 1), were provided by the China Meteorological Data Network (http://data.cma.cn); the stations were Yulin, Dingbian, Wuqi, Hengshan, Suide, Yan'an, Hequ, Xingxian, Luochuan, Huanxian, and Yaozhou; (2) ASTER DEM (Digital Elevation Model) data of $30 \mathrm{~m}$ resolution, collected from the National Science Data Mirroring Website of the Computer Network Information Center, Chinese Academy of Science (http://www.gscloud.cn); (3) soil type distribution, using a 1:50,000 map; (4) $250 \mathrm{~m}$ resolution and 16d synthesized Normalized Difference Vegetation Index (NDVI) from the Moderate Resolution Imaging Spectroradiometer (MODIS) from 2000 to 2014, downloaded from http://lpdaac.usgs.gov; (5) land use data for the province Shaanxi for the years 2000, 2005, and 2010, at a scale of 1:100,000, collected from the "Remote Sensing Survey and Assessment of the Ten Years of National Ecological Environment Change (2000-2010)". All data were resampled to 30-m resolution for calculation and statistical analysis. 


$$
-4168-
$$

\section{Methods}

The Revised Universal Soil Loss Equation (RUSLE) is a mature and widely used calculation method of the soil erosion modulus, using the following formula (Eq. 1; Renard et al., 1991):

$$
A=R \times K \times L \times S \times C \times P
$$

where

$A$ is the soil erosion modulus, $\mathrm{t} /\left(\mathrm{km}^{2} \cdot \mathrm{a}\right)$;

$R$ is the rainfall erosivity factor, $(\mathrm{MJ} \cdot \mathrm{mm}) /\left(\mathrm{hm}^{2} \cdot \mathrm{h} \cdot \mathrm{a}\right)$;

$K$ is the soil erodibility factor;

$L$ is the slope length factor;

$S$ is the slope factor;

$C$ is the vegetation cover factor; and

$P$ is the soil and water conservation factor.

\section{Rainfall erosivity factor $(R)$}

The $R$ factor is the indicator for evaluating the impact of rainfall on soil separation and transportation. Annual rainfall erosivity is calculated (Eqs. 2, 3 and 4) using daily rainfall data as proposed in Zhang et al. (2002, 2003) and Xie et al. (2000):

$$
\begin{gathered}
R_{i}=a \sum_{j=1}^{n} D_{j}^{b} \\
a=21.586 b^{-7.1891} \\
b=0.8363+18.144 D_{d 12}^{-1}+24.455 D_{y 12}^{-1}
\end{gathered}
$$

where

$R_{i}$ is the rainfall erosivity in the $i$ year $(\mathrm{MJ} \cdot \mathrm{mm}) /\left(\mathrm{hm}^{2} \cdot \mathrm{h} \cdot \mathrm{a}\right)$;

$D_{j}$ is the erosive rainfall on the $j$ th day, $\mathrm{mm}$;

$n$ is the total time of erosive rainfall in a year, $\mathrm{d}$;

$D_{d 12}$ is the multi-year average daily rainfall of daily rainfall $\geq 12 \mathrm{~mm} / \mathrm{d}, \mathrm{mm}$;

$D_{y 12}$ is the multi-year average annual rainfall of daily rainfall $\geq 12 \mathrm{~mm} / \mathrm{d}, \mathrm{mm}$; and $a$ and $b$ are the model parameters.

\section{Soil erodibility factor $(K)$}

The $K$ factor is the indicator to evaluate soil erosion probability when rainfall erosivity has occurred. The calculated method has been proposed by Sharpley and Williams (1990), using Equation 5:

$$
\begin{aligned}
K= & \{0.2+0.3 \exp [0.0256 M(1-F / 100)]\} \times(F /(F+M))^{0.3}[1.0-0.25 T(T+ \\
& \exp (3.72-2.95 T)] \times\{1.0-0.7 \delta /[\delta+\exp (-5.51+22.9 \delta)]\}
\end{aligned}
$$

where

$M$ is the mass fraction of sand, $\%$; 


$$
-4169 \text { - }
$$

$F$ is the mass fraction of silt, \%;

$N$ is the mass fraction of clay, \%;

$T$ is the mass fraction of soil organic carbon, \%; and

$\Delta=1-M / 100$;

The $K$ value is needed to use the international system units through multiplication by 0.1317 .

\section{Topographical factor $(L S)$}

Slope length and slope $(L S)$ are the topographical factors mainly reflecting the effects of topography on soil erosion. The formulae are expressed as follows (Eqs. 6, 7, 8, 9 and 10; Moore and Wilson, 1992; Liu et al., 1994; Renard et al., 1997):

$$
\begin{gathered}
L=(\lambda / 22.13)^{\alpha} \\
\alpha=\frac{\beta}{\beta+1} \\
\beta=(\sin \theta / 0.0896) /\left[3.0 \times(\sin \theta)^{0.8}+0.56\right] \\
S=\left\{\begin{array}{c}
10.8 \sin \theta+0.03, \theta<9 \% \\
16.8 \sin \theta-0.50,9 \% \leq \theta<14 \% \\
21.9 \sin \theta-0.96, \theta \geq 14 \% \\
L S=L \times S
\end{array}\right.
\end{gathered}
$$

where

$\lambda$ is the slope length, calculated using the hydrological analysis module in the ArcMap on the basis of $30 \mathrm{~m}$ resolution DEM;

$\alpha$ is the slope length index;

$\theta$ is the slope in \%, obtained by the surface analysis tool in ArcMap and based on $30 \mathrm{~m}$ DEM;

The $L S$ value is calculated by multiplying $\mathrm{L}$ by the $\mathrm{S}$ value, according to the Equations $6,7,8$ and 9.

\section{Vegetation cover factor $(C)$}

The $\mathrm{C}$ factor is the vegetation index, which is calculated based on MODIS NDVI data; the formula is expressed as follows (Eqs. 11 and 12; Li and Zheng, 2012):

$$
\begin{gathered}
N D V I_{A}=0.18 \times N D V I_{M}+0.131 \\
C=\exp \left[-c \times \frac{N D V I_{A}}{d-N D V I_{A}}\right]
\end{gathered}
$$

where

The $c$ value is 2 , and the $d$ value is 1 ; 
$N D V I_{A}$ and $N D V I_{M}$ represent the AVHRR (Advanced Very High Resolution Radiometer) NDVI and MODIS NDVI data, respectively.

Soil and water conservation factor $(P)$

Use the calculation method (Eq. 13) proposed by Lufafa et al. (2002):

$$
P=0.2+0.03 \theta
$$

The results of the soil erosion modulus and various factors in the WDRB and LHRB in LPNSC were calculated using RUSLE (Fig. 2).

\section{Wuding River Basin}

(a)

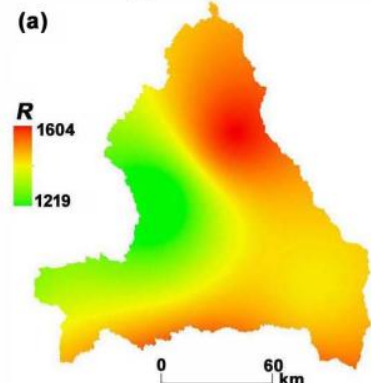

(d)

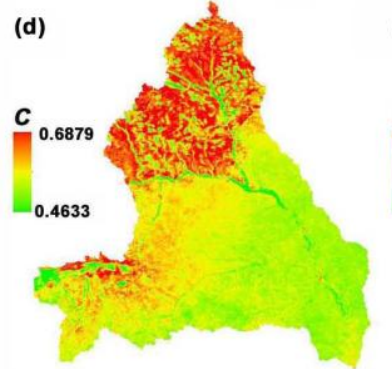

(b)

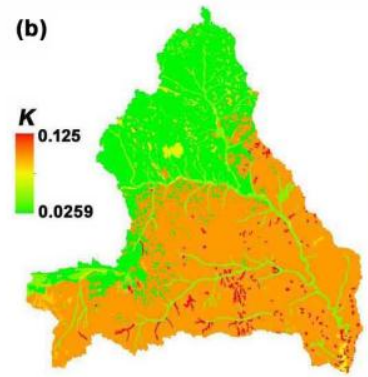

(e)

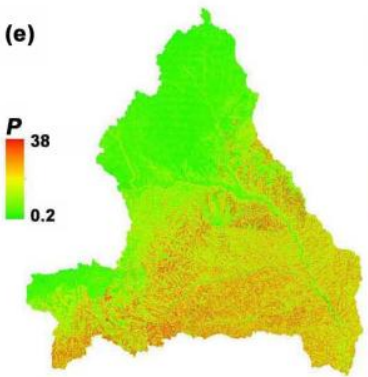

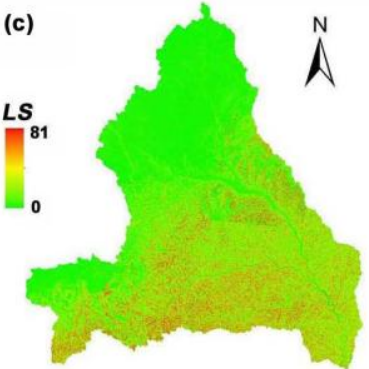

(f)

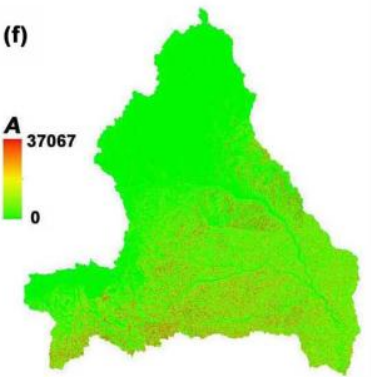

Luohe River Basin

(g)

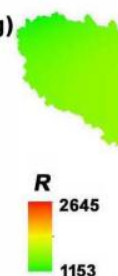

(h)

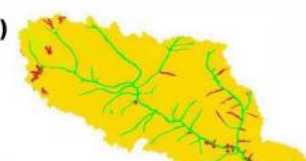

(i)
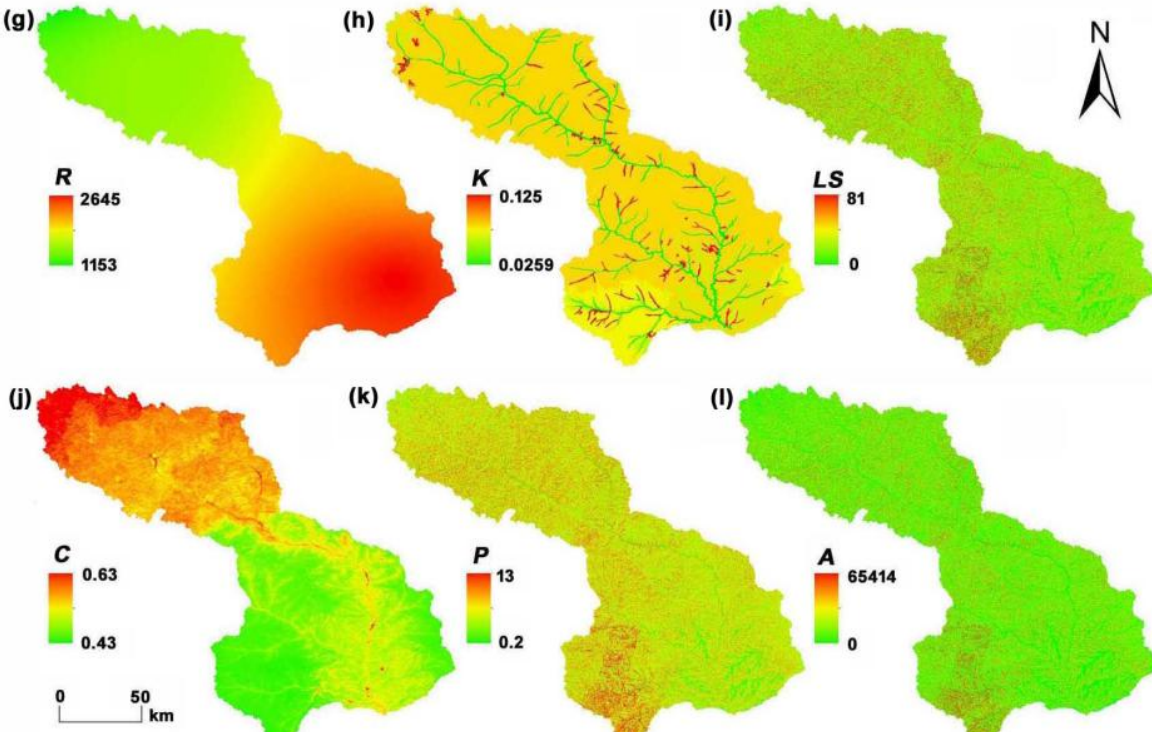

(k)
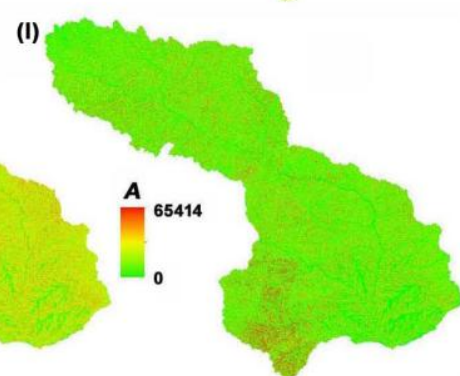

Figure 2. Results of soil erosion modulation and its factors in the Wuding River Basin and Luohe River Basin. The maps present average values (2000 to 2014) for rainfall erosivity ( $R$; $(M J \cdot m m) /(h m \cdot h \cdot a))$, vegetation cover factor $(C)$, and soil erosion modulus $\left(A ; t /\left(\mathrm{km}^{2} \cdot a\right)\right)$ 


\section{Results}

\section{Impacts of GGP implementation on land use and NDVI change}

\section{Land use and NDVI change}

The main land use types in the WDRB were grassland, farmland, and idle land. Affected by the implementation of the GGP, land use in the basin underwent major changes between 2000 and 2010. In general, the areas of farmland and idle land decreased, while other land use types increased. The large reduction in farmland area and the large increase in grassland area indicate that a large amount of farmland was turned into grassland. In addition, the farmland area decreased, while grassland areas increased between 2000 and 2005; the changes were higher than those between 2005 and 2010, indicating that in the WDRB, the impact of GGP implementation on land use change was concentrated in the years between 2000 and 2005 (Fig. 3a). Despite the largest reduction and increase in farmland and grassland areas, respectively, between 2000 and 2010, construction land also increased, namely by $162.18 \%$. This reflects the ongoing and considerable growth of the urban area as well as of industrial and mining land (Fig. 3b).

The main land use types in the LHRB were forest land, grassland, and farmland. As a consequence of the implementation of the GGP between 2000 and 2010, farmland areas declined mostly, while grassland areas considerably increased, followed by forested land. Such changes were concentrated in the period 2000-2005, while between 2005 and 2010, only slight changes occurred (Fig. 3c). Adhering to the main objectives of the GGP, farmland areas were transformed into forests and grasslands. Compared with the year 2000, $19.52 \%$ of the farmland was reduced in 2010, while construction land increased more than forest and grassland, reaching 39.58\% (Fig. 3d).

The impact of GGP implementation on land use changes was concentrated between 2000 and 2005, resulting in a large reduction in farmland and a large increase in grassland. However, there was a lower forest land area in the WDRB, and the farmland was converted into grassland, while in the LHRB, farmland was mainly converted into the forest. Furthermore, in the WDRB, the construction land increased more than in the LHRB, reflecting the economic and social development.

The NDVI is an important indicator of the level of surface vegetation. The vegetation in the WDRB was dominated by temperature grassland, and that in the LHRB was dominated by temperature forest. The NDVI value was higher in the LHRB compared to the WDRB. However, affected by the implementation of the GGP, the average annual NDVI of the WDRB increased from 0.3103 to 0.5038 (61.38\%) from 2000 to 2014, while the NDVI in the LHRB increased from 0.6052 to $0.7233(19.52 \%)$ in the same period; both trends were linear. The growth rates were 0.0128/a and 0.0083/a, respectively, above the significance level of 0.001 , which indicates that the NDVI in the two basins will continue to increase (Fig.3e).

\section{Land use and NDVI change at different slopes}

Areas with a slope $\geq 25^{\circ}$ were the main objectives in the GGP implementation. Changes in land use and NDVI in regions $<25^{\circ}$ and $\geq 25^{\circ}$ were calculated, and the effects of the implementation of the GGP were compared. The results are shown in Figure 4. 

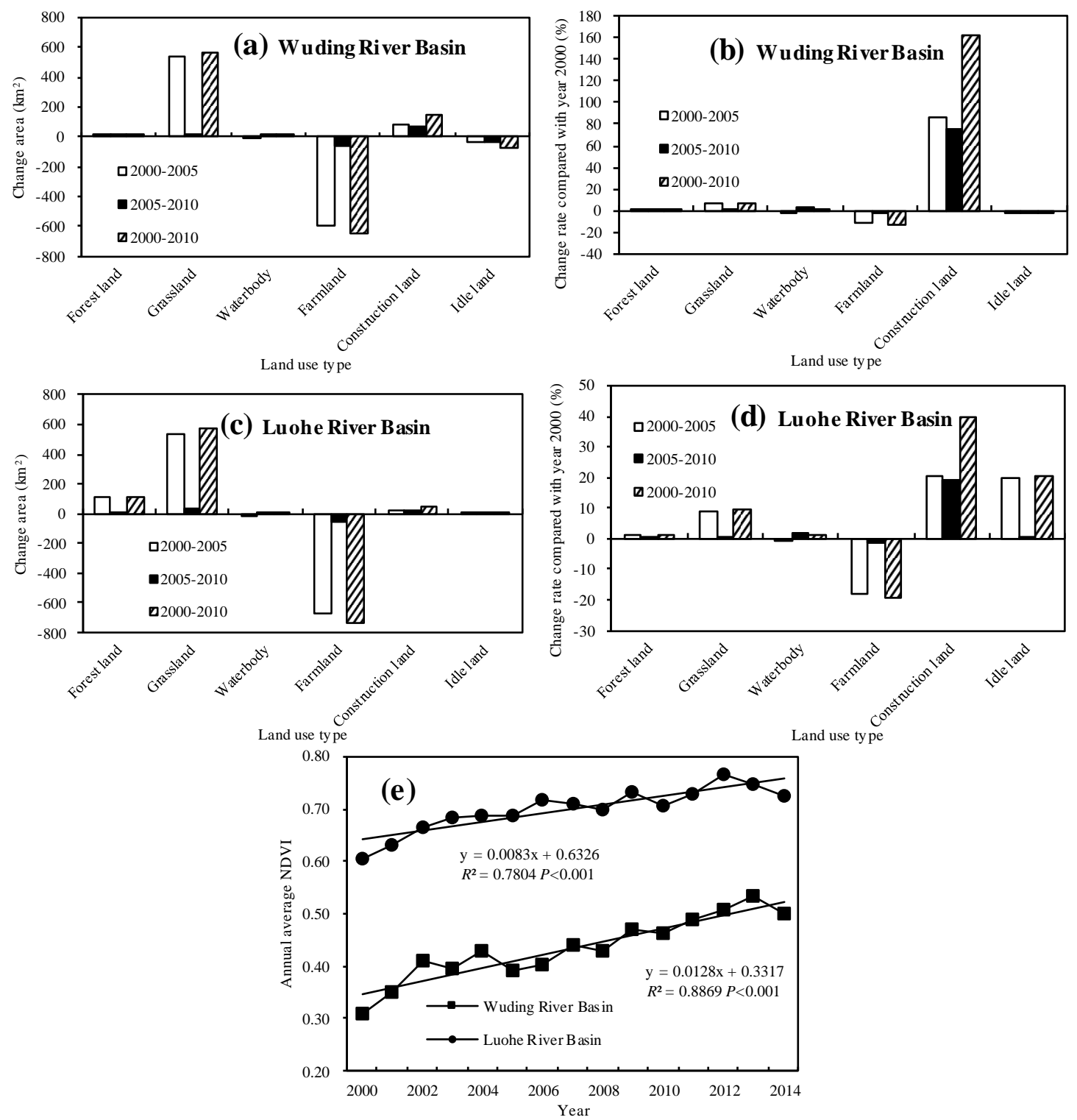

Figure 3. The area of land use change, change rate compared between year 2000 and 2010, and change trend of annual average NDVI from 2000 to 2014 in the Wuding River Basin and Luohe River Basin. Figure (a) and (b) show the areas of land use change in different periods for Wuding River Basin during 2000-2010 and the percentage of change area compared with 2000, respectively. Figure $(c)$ and $(d)$ show the areas of land use change in different periods for Luohe

River Basin during 2000-2010 and the percentage of change area compared with 2000, respectively. Figure (e) shows the annual average NDVI change trend for Wuding River Basin and Luohe River Basin from 2000 to 2014

Land use change at different slopes can also cause changes in NDVI. In the WDRB, the NDVI value of the area with slopes $\geq 25^{\circ}$ was higher than that of the area with slopes $<25^{\circ}$. The NDVI of both regions showed a linear increase from 2000 to 2014, with linear growth rates of $0.0157 / \mathrm{a}$ and $0.0127 / \mathrm{a}$, respectively. These results indicate that the growth rate of NDVI in areas $\geq 25^{\circ}$ was higher than that in areas $<25^{\circ}$, and the NDVI in the two regions is expected to continue to increase in the future (Fig. 4e). The situation in the LHRB was similar to that in the WDRB. The NDVI value in the $\geq 25^{\circ}$ 
region was higher than that in the $<25^{\circ}$ region, and all showed a linear increase; linear growth rates were $0.0078 / \mathrm{a}$ and $0.0084 / \mathrm{a}$, respectively. Based on these results, we assume that the NDVI growth rate in areas $<25^{\circ}$ was higher than that in areas $\geq 25^{\circ}$, which may be related to the better vegetation coverage in the LHRB and the effects of GGP implementation (Fig. 4f).
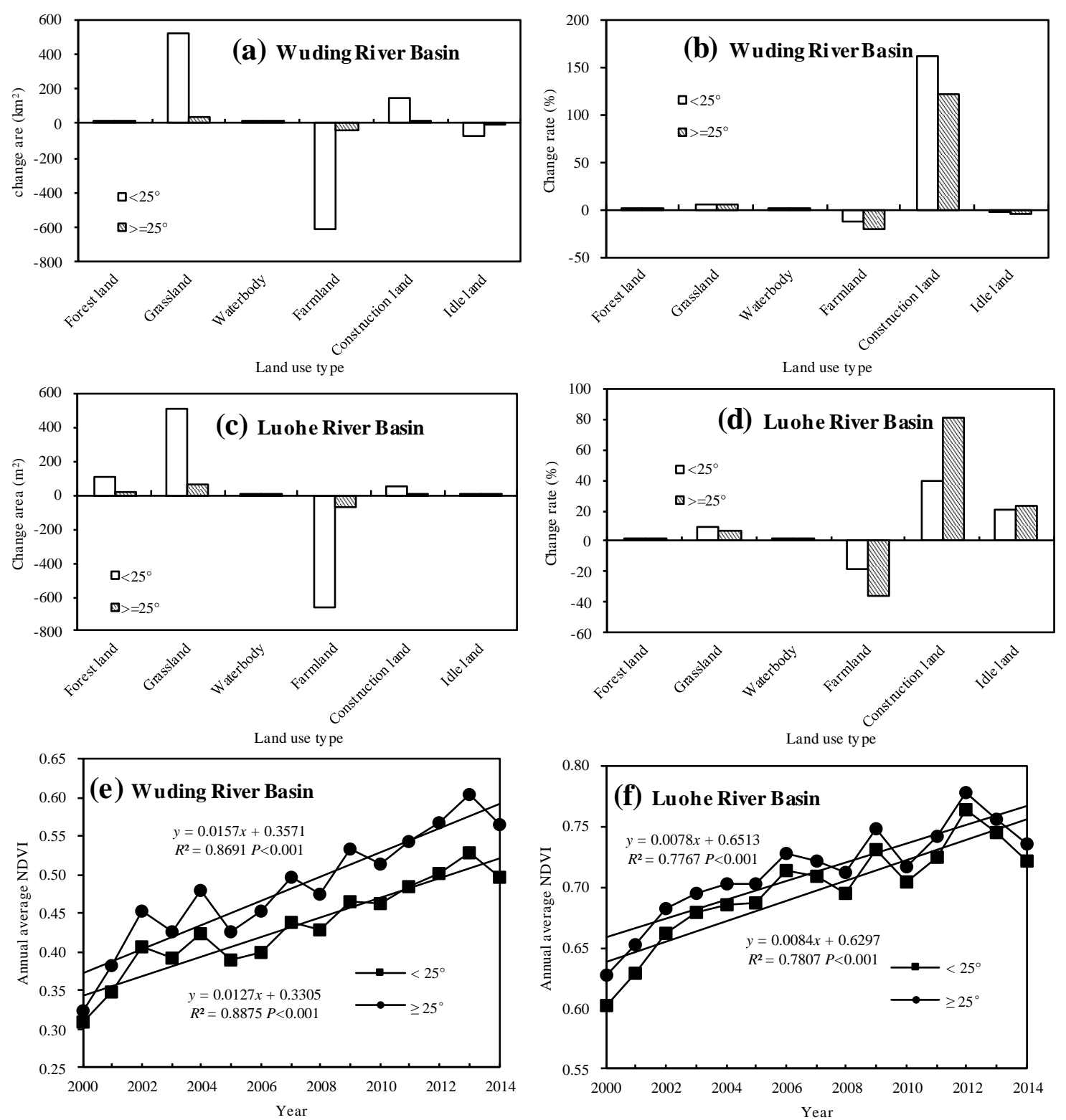

Figure 4. Area, rate of land use change, and change trend of NDVI at different slopes between 2000 and 2014 in the Wuding River Basin and Luohe River Basin. Figure (a) and (b) show the areas of land use change in different periods for Wuding River Basin during 2000-2010 and the percentage of change area compared with 2000, respectively. Figure (c) and (d) show the areas

of land use change in different periods for Luohe River Basin during 2000-2010 and the percentage of change area compared with 2000, respectively. Figure e and $(f)$ show the annual average NDVI change trend for Wuding River Basin and Luohe River Basin from 2000 to 2014, respectively 


$$
-4174 \text { - }
$$

\section{Soil erosion modulus change at different slopes}

The soil erosion modulus at different slopes as well as the anomalies for each year were calculated (Fig. 5). The annual average soil erosion modulus for both sites from 2000 to 2014 at a slope $<25^{\circ}$ was lower than that of the slope $\geq 25^{\circ}$. Annual average soil erosion modulus in the area of $<25^{\circ}$ in the WDRB was only $277.26 \mathrm{t} /\left(\mathrm{km}^{2} \cdot \mathrm{a}\right)$, while that in the $\geq 25^{\circ}$ region was $4,362.99 \mathrm{t} /\left(\mathrm{km}^{2} \cdot \mathrm{a}\right)$. In the LHRB, the annual average soil erosion modulus in the $<25^{\circ}$ region was $1,335.96 \mathrm{t} /\left(\mathrm{km}^{2} \cdot \mathrm{a}\right)$, while in the region $\geq 25^{\circ}$, this value was $5,109.25 \mathrm{t} /\left(\mathrm{km}^{2} \cdot \mathrm{a}\right)$. Based on the results, the slope of an area had a impact on land use change. However, for any area, the slope was fixed and relatively small. The vegetation attached to the slope surface was affected by climatic changes and human activities, such as GGP implementation.

The decrease in farmland and the increase in grassland and forest land were concentrated in 2000-2005. Given the changes in land use and soil erosion modulus at different slopes (Figs. 4 and 5), the soil erosion modulus of the WDRB from 2000 to 2007 (except for 2001) was lower than the average value from 2000 to 2014, while after 2008 (except for 2010), the soil erosion modulus increased and was higher than the multi-year average value (Fig. 5a). This can be explained by the relatively sparse precipitation in the WDRB in 2000-2005 and affected by the implementation of the GGP. The surface vegetation coverage increased and the soil erosion modulus decreased; but under extreme precipitation in the following period, the soil erosion modulus increased (Wang et al., 2014c, d).

Vegetation coverage in the LHRB was relatively high, especially in the southeast of the basin. Therefore, GGP implementation further increased the level of vegetation cover in the basin and caused the decline of the soil erosion modulus. The soil erosion modulus anomalies for most years were negative from 2000 to 2014, which indicated that the inter-annual precipitation variability increased, resulting in an extremely high soil modulus. Therefore, the mean value from 2000 to 2014 also increased, and most of the year's anomalies showed a negative value (Fig. $5 b$ ).
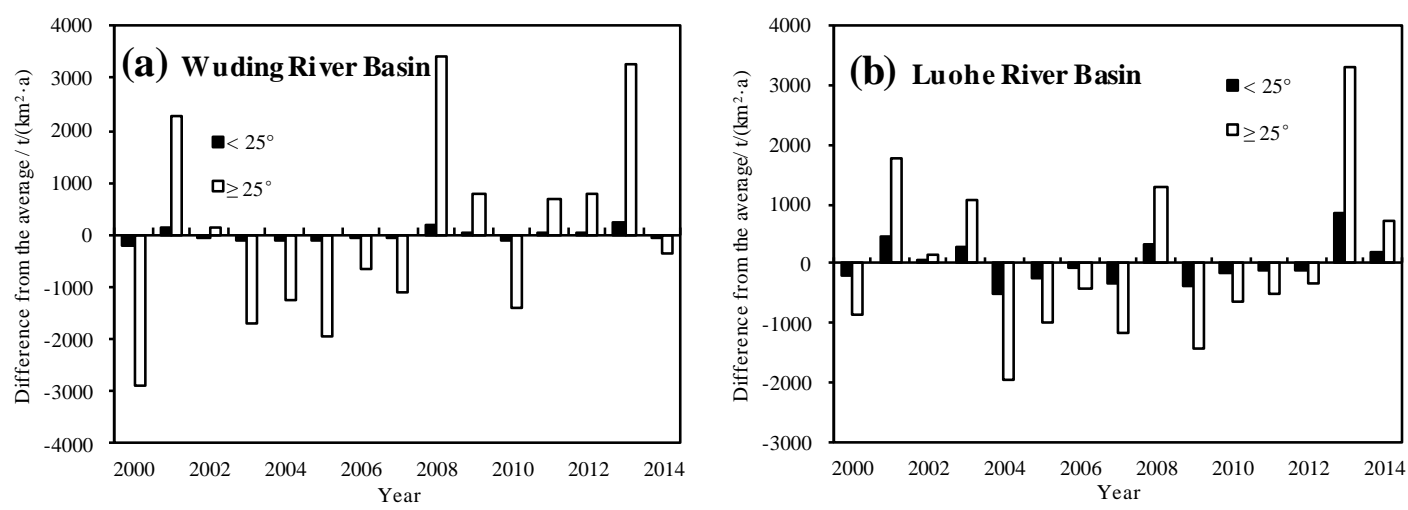

Figure 5. Differences between annual soil erosion modulus and the average value between 2000 and 2014 at different slopes in the Wuding River Basin and Luohe River Basin

\section{Temporal and spatial changes of soil erosion modulus}

Annual sediment transport data of the Baijiachuan hydrological station in the WDRB and the Zhuangtou hydrological station in the LHRB were obtained by the Yellow River Water Resource and Sediment Bulletin. The multi-year average soil erosion modulus of 
the WDRB in LPNSC, from 2000 to 2014, was $457.90 \mathrm{t} /\left(\mathrm{km}^{2} \cdot \mathrm{a}\right)$, slightly higher than the average soil erosion modulus of $419.30 \mathrm{t} /\left(\mathrm{km}^{2} \cdot \mathrm{a}\right)$ measured by the Baijiachuan hydrological station, while the soil erosion modulus in the LHRB was $1,843 \mathrm{t} /\left(\mathrm{km}^{2} \cdot \mathrm{a}\right)$, slightly lower than the $2,150 \mathrm{t} /\left(\mathrm{km}^{2} \cdot \mathrm{a}\right)$ measured by the Zhuangtou hydrological station. The estimated soil erosion modulus was higher in the WDRB in LPNSC, while in the LHRB, the estimated values were lower; however, the overall difference was relatively low.

\section{Temporal changes}

Soil erosion in LPNSC is serious, but there are obvious differences in soil erosion levels between the different watersheds. Figure 6 showed that, in general, the soil erosion modulus in the LHRB was higher than that in the WDRB, and the multi-year average soil erosion modulus was different. This mainly reflects the dominant role of precipitation in the soil erosion process. The LHRB is located in the southern part of the northern Shaanxi Province, and annual precipitation is higher than that in the WDRB in the northern part of the northern Shaanxi Province. Moreover, the climatic conditions and the vegetation coverage in the LHRB are relatively better than those in the WDRB. Therefore, the soil erosion modulus in the LHRB was higher than that in the WDRB, which can be attributed to the difference in precipitation. From 2000 to 2014, the soil modulus in the LHRB and the WDRB showed a fluctuating increase, and the linear increase rate of the soil erosion modulus in the LHRB was higher than that in the WDRB, although the linear fitting results were insignificant $(P>0.05)$, reflecting the inconsistency of the soil erosion change in both sites.

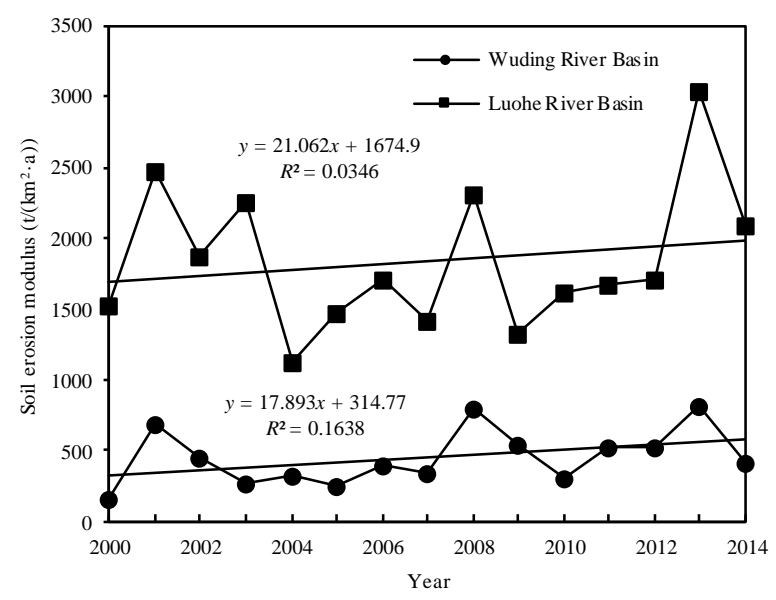

Figure 6. Changes in annual average soil erosion modulation in the Wuding River Basin and Luohe River Basin

\section{Spatial change process}

The linear change rate, the linear change trend, and the $F$ test results for LHRB and WDRB were calculated by the linear trend method, using data from 2000 to 2014. The results are shown in Figure 7.

The linear change rate of the soil erosion modulus in the WDRB from 2000 to 2014 ranged between -230 and $1756 \mathrm{t} / \mathrm{km}^{2}$ per year; higher values were mainly distributed in the southeast of the basin and in the southern part of the hilly-gully area, while the 
northwestern and western parts belong to the southern margin of the $\mathrm{Mu}$ Us Sandy Land, with low-lying land, less rainfall, less soil erosion, and a relatively small change rate in soil modulus (Fig. 7a). The linear change rate was higher than 0 and lower than 0 , which means that the soil erosion modulus in WDRB increased and decreased from 2000 to 2014. The changing trend of the soil erosion modulus mainly increased, accounting for $99.6 \%$ of the total basin area, while decreases accounted for $0.45 \%$, concentrated in the northern part of the basin (Fig. $7 b$ ). The $F$ test results showed that the linear change of the soil erosion modulus in the WDRB was mainly insignificant, accounting for $79.3 \%$ of the total basin area, while the area with a trend of significant change accounted for $20.7 \%$, concentrated in the south-east of the basin. The soil erosion modulus of the hilly-gully region of the Loess Plateau, located in the southeast of the WDRB, continues to increase, with a critical soil erosion situation (Fig. 7c).

The linear change rate of the soil erosion modulus in the LHRB ranged between -584 and $992 \mathrm{t} / \mathrm{km}^{2}$ per year, which was smaller than that in the WDRB; however, both rates are still relatively high. High values were mainly concentrated in the middle area and the central southwest of the watershed (Fig. 7d). The northern part of the LHRB is a loess hilly-gully region, which is dominated by grassland and showed serious soil erosion. The central and southern parts were covered by temperate forest, with a relatively high vegetation coverage and low soil erosion low (Fig. 2I). Overall, there was an increasing change, accounting for $73.3 \%$ of the total area of the basin, while the decreasing accounting for $26.7 \%$, mainly in the southeastern and northern parts of the basin (Fig. $7 e$ ). The results of the $F$ test showed that the linear change of the soil erosion modulus in the LHRB was mainly insignificant, accounting for $99.3 \%$, while a significant trend was sparsely distributed along the northern margins in the basin (Fig. 7f).

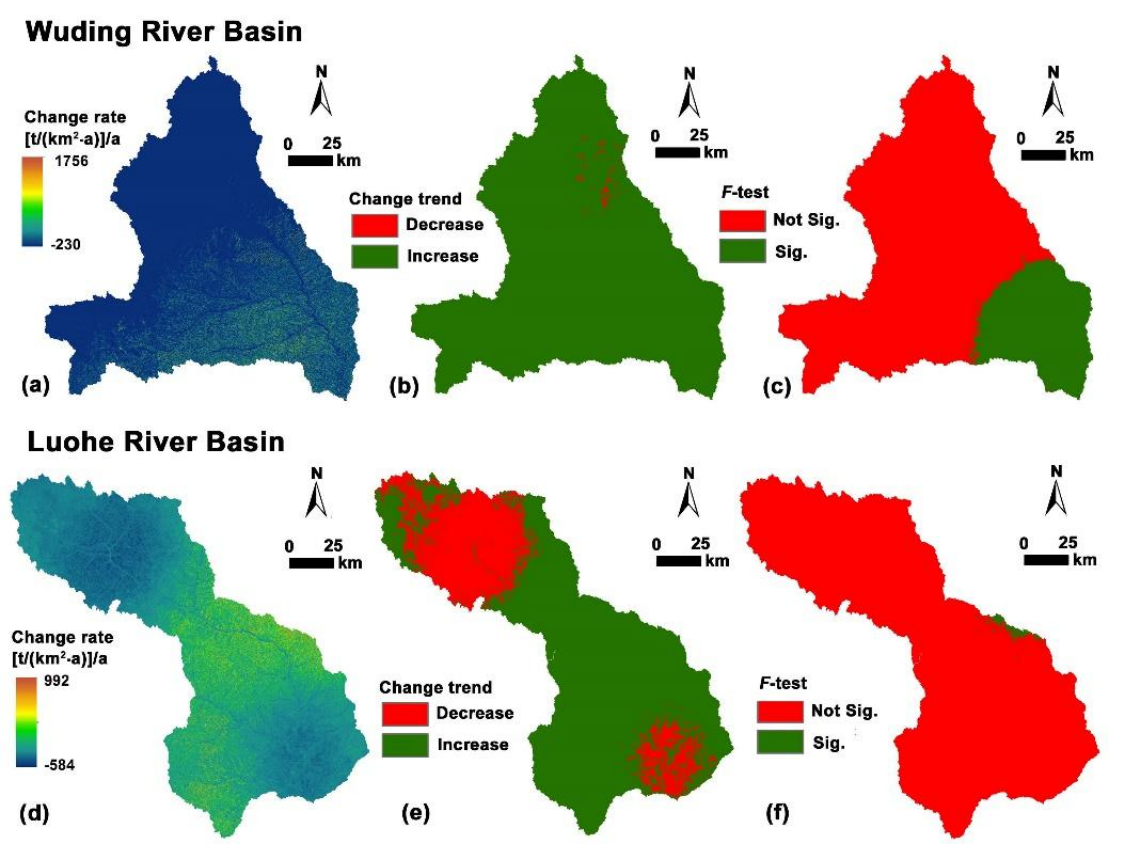

Figure 7. The change rate, the change trend, and the $F$ test results of soil erosion modulation for Wuding River Basin and Luohe River Basin. Figure (a), (b), and (c) represent the change rate, the change trend, and the F test result for Wuding River Basin, respectively; Figure (d), $(e)$, and $(f)$ represent the change rate, the change trend, and the F test result for Luohe River Basin, respectively 


$$
-4177 \text { - }
$$

\section{Impacts of GGP implementation on soil erosion}

To assess the impacts of GGP implementation on soil erosion, it is assumed that the soil erodibility factor $(K)$, the topography factor $(L S)$, and the soil and water conservation factor $(P)$ are fixed, while the rainfall erosivity factor $(R)$ and the vegetation cover factor $(C)$ varied over the years. In terms of the $R$ and $C$ factor, the former was not controllable, while the latter could be affected by GGP implementation. When $R$ is fixed, the erosive forces in 2000 would remain unchanged from 2000 to 2014 , only the impact of the $C$ factor (NDVI) on soil erosion would be considered. The results are shown in Figure 8.
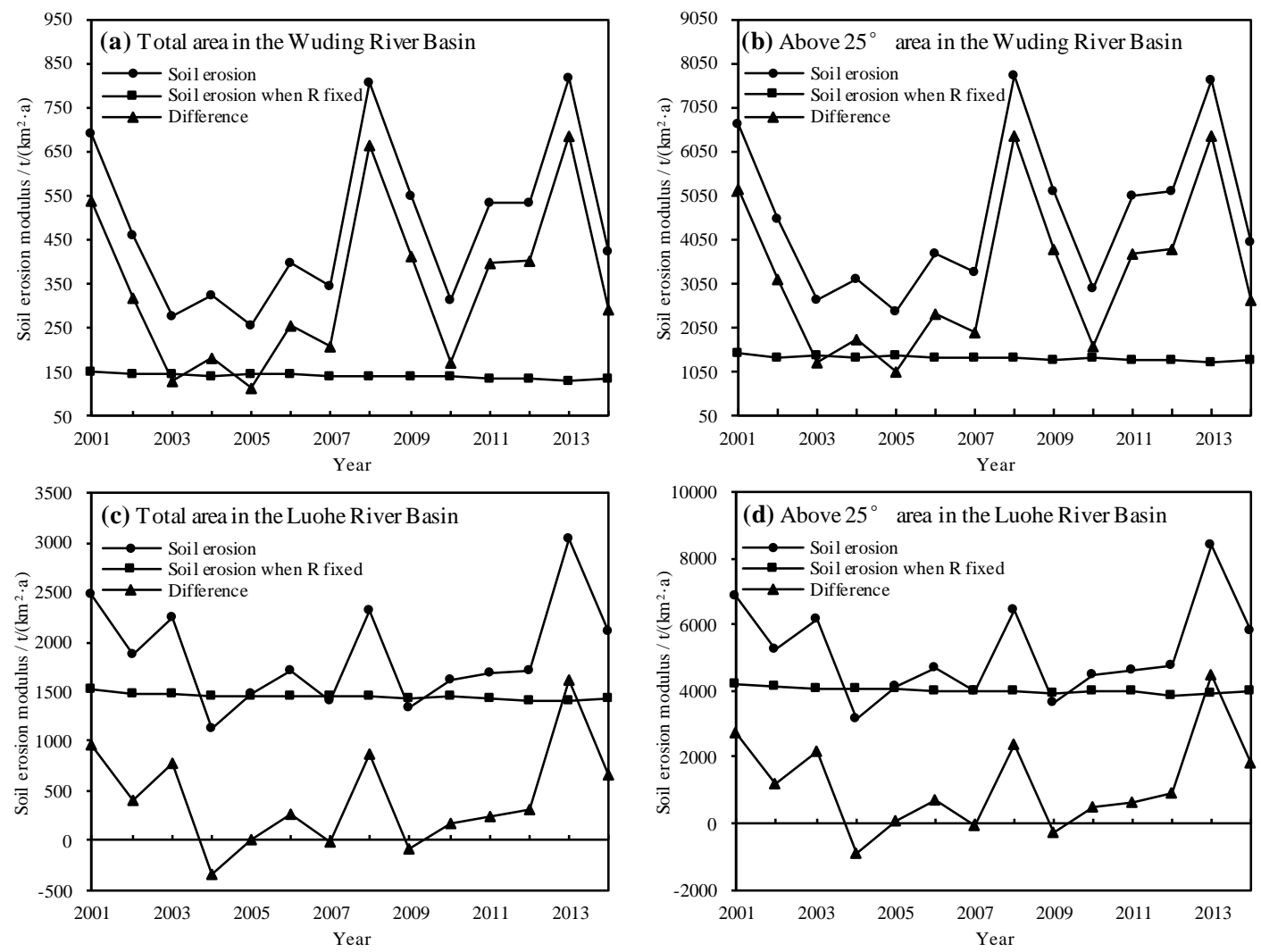

Figure 8. Soil erosion modulus change in the entire region and areas with a slope $\geq 25^{\circ}$, with fixed $R$ values, and the difference between soil erosion modulus in actual and when $R$ fixed in 2000, from 2001 to 2014 in the Wuding River Basin and Luohe River Basin

The soil erosion modulus in both WDRB and LHRB during 2000-2014 increased. When the change of rainfall erosivity was not taken into account, the soil erosion in the two basins was only affected by the surface vegetation changes. The soil erosion modulus in both basins showed decline (Fig. $8 a$ and $c$ ). The $\geq 25^{\circ}$ regions were the key areas for GGP implementation, and the soil erosion modulus at these regions also showed reduction (Fig. $8 b$ and $c$ ). At areas with a slope $\geq 25^{\circ}$, the soil erosion modulus in the two basins was 9.5 times and 2.7 times higher than the total soil erosion modulus, respectively, which indicated that the implementation of GGP had reduced the soil erosion modulus by changing the surface vegetation coverage. However, it should also be noted that in the natural state, the soil erosion modulus increased from 2000 to 2014 , 


$$
-4178-
$$

which means that the increase in the soil erosion modulus caused by precipitation changes far exceeded the reduction caused by the implementation of the GGP.

\section{Discussion}

Using the WDRB and LHRB as examples, the implementation of the GGP changed the land use types and affected the vegetation status (reflected by changes in NDVI), thereby reducing soil erosion. However, there are a large number of factors influencing soil erosion, which is a quite complex process.

In the RUSLE model, the soil erodibility factor is mainly affected by the organic matter content in the soil and the mechanical composition of soil particles. The GGP implementation in the first stage (2000-2008) has caused obvious changes in soil organic matter content (Zhu et al., 2014; Xie et al., 2016). The soil erodibility factor changes over time, and under objective conditions, the use of a year-by-year soil erodibility factor to calculate the soil erosion modulus will be closer to the actual situation.

Positive soil erosion modulus values in the WDRB and LHRB from 2000 to 2014 were six and five years, respectively. However, the overall increase in soil erosion in the two basins indicates that severe soil erosion will occur within a few years, caused by heavy precipitation (Fig.9). The role of precipitation in soil erosion is obvious. The construction of check dams for channel treatment and the implementation of the GGP for slope vegetation treatment have already been performed. However, with the increase of the frequency of extreme precipitation caused by climate change, the changes in soil erosion in the basins require further research.
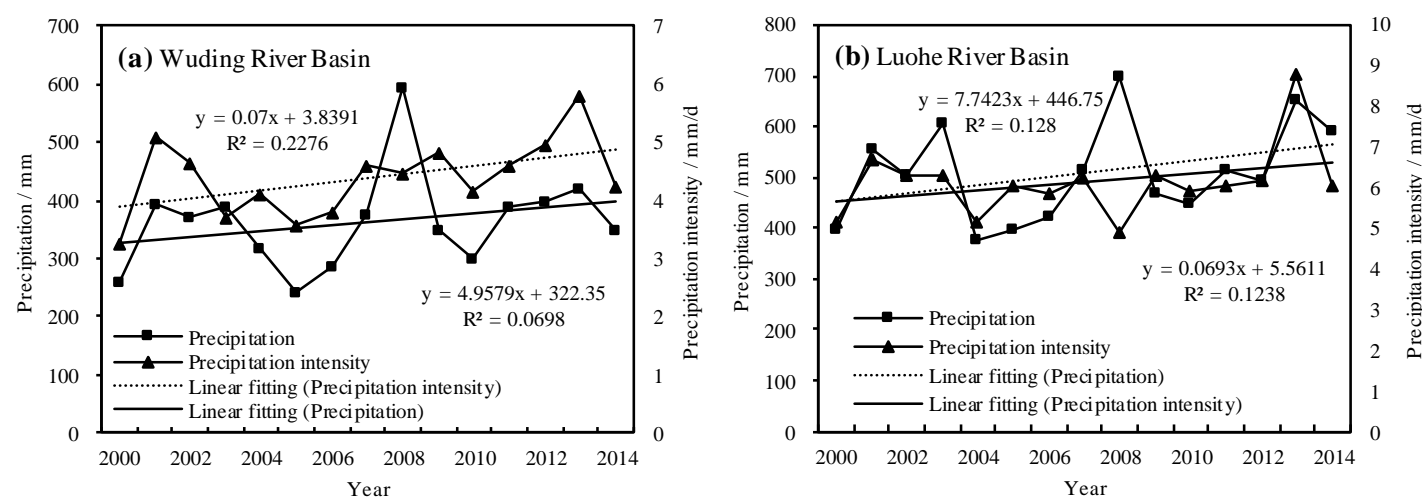

Figure 9. Precipitation and precipitation intensity change from 2000 to 2014 in the Wuding River Basin and Luohe River Basin

\section{Conclusions}

(1) The implementation of the GGP (2000-2008) promoted the conversion of farmland to grassland and forest land (concentrated in 2000-2005) in the WDRB and LHRB. In 2000-2014, the NDVI values increased by 61.38 and $19.52 \%$ in the WDRB and LHRB, respectively, and showed a linear increase; the change rates of land use and NDVI in the area with a slope $\geq 25^{\circ}$ were higher than those in $<25^{\circ}$ areas and throughout the basin. The change range of soil erosion modulus difference value at a 
slope $\geq 25^{\circ}$ was higher than that at a slope $<25^{\circ}$, and the negative value reflected the role of the GGP, while the positive value reflected the rainfall impact.

(2) The soil erosion modulus values of both basins increased from 2000 to 2014, and the average soil erosion modulus and its growth rate in the LHRB were higher than those in the WDRB, which is mainly due to the difference in rainfall. The soil erosion modulus in both basins mainly showed an increase and areas with increase were mainly distributed in the southeastern region of the WDRB (20.7\%), and the northern of the LHRB (only $0.7 \%$ ).

(3) Without considering the impact of changed precipitation, the soil erosion modulus of both basins from 2000 to 2014 showed a decrease; the linear decline rate of the soil erosion modulus in the region with a slope $\geq 25^{\circ}$ was 9.7 and 2.5 times than that of the whole basin in the WDRB and LHRB, respectively. This proves that the implementation of the GGP, converting farmland into forest land and grassland, has improved the vegetation coverage (especially in areas with a slope $\geq 25^{\circ}$ ) and consequently reduced soil erosion.

This paper analyzed the process by which soil erosion in the Wuding River Basin and Luohe River Basin in northern Shaanxi Province of China has changed based on the RUSLE. However, the research lacks support from measured data. Future studies should obtain hydrological monitoring data and compare this with the results calculated by RUSLE.

Acknowledgements. This work was supported by the National Key Research and Development Program of China (2016YFC0501707), the National Natural Science Foundation of China (41671086, 41501571), and the Open Foundation of State Key Laboratory of Soil Erosion and Dryland Farming of the Loess Plateau (A314021402-1616).

\section{REFERENCES}

[1] Dong, S. C., Cheng, H., Li, Y., Li, F. J., Wang, Z., Chen, F. (2017): Rural landscape types and recreational value spatial analysis of valley area of Loess Plateau: A case of Hulu Watershed, Gansu Province, China. - Chinese Geographical Science 27(2): 286297.

[2] Feng, X. M., Cheng, W., Fu, B. J., Lyu, Y. H. (2016): The role of climatic and anthropogenic stresses on long-term runoff reduction from the Loess Plateau, China. Science of the Total Environment 571: 688-698.

[3] Gao, H. D., Li, Z. B., Jia, L. L., Li, P., Xu, G. C., Ren, Z. P., Pang, G. W., Zhao, B. H. (2016): Capacity of soil loss control in the Loess Plateau based on soil erosion control degree. - Journal of Geographical Sciences 26(4): 457-472.

[4] Gao, H. D., Pang, G. W., Li, Z. B., Cheng, S. D. (2017): Evaluating the potential of vegetation restoration in the Loess Plateau. - Acta Geographica Sinica 72(5): 863-874 (in Chinese).

[5] Hu, C. J., Liu, G. H., Fu, B. J., Chen, L. D., Lyu, Y. H., Guo, L. (2014): Soil carbon stock and flux in plantation forest and grassland ecosystem in Loess Plateau, China. - Chinese Geographical Science 24(4): 423-435.

[6] Jiang, C., Zhang, H. Y., Zhang, Z. D. (2018): Spatially explicit assessment of ecosystem services in China's Loess Plateau: patterns, interactions, drivers, and implications. Global and Planetary Change 161: 41-52. 


$$
-4180 \text { - }
$$

[7] Jiao, J. Y., Wang, Z. J., Zhao, G. J., Wang, W. Z., Mu, X. M. (2014): Changes in sediment discharge in a sediment-rich region of the Yellow River from 1955 to 2010: implications for further soil erosion control. - Journal of Arid Land 6(5): 540-549.

[8] Li, S., Liang, W., Fu, B. J., Lyu, Y. H., Fu, S. Y., Wang, S., Su, H. M. (2016): Vegetation changes in recent large-scale ecological restoration projects and subsequent impact on water resources in China's Loess Plateau. - Science of the Total Environment 569: 10321039.

[9] Li, T. H., Zheng, L. N. (2012): Soil erosion changes in the Yanhe watershed from 2001 to 2010 based on RUSLE model. - Journal of Natural Resources 27(7): 1164-1175 (in Chinese).

[10] Li, Z. W., Zhang, G. H., Geng, R., Wang, H., Zhang, X. C. (2015): Land use impacts on soil detachment capacity by overland flow in the Loess Plateau, China. - Catena 124: 917.

[11] Li, Z. W., Liu, C., Dong, Y. T., Chang, X. F., Nie, X. D., Liu, L., Xiao, H. B., Lu, Y. M., Zeng, G. M. (2017): Response of soil organic carbon and nitrogen stocks to soil erosion and land use types in the Loess hilly-gully region of China. - Soil \& Tillage Research 166: $1-9$.

[12] Liu, B. Y., Nearing, M. A., Risse, L. M. (1994): Slope gradient effects on soil loss for steep slopes. - Transactions of the ASAE 27(6): 1835-1840.

[13] Liu, Q. J., Shi, Z. H., Yu, X. X., Zhang, H. Y. (2014): Influence of microtopography, ridge geometry and rainfall intensity on soil erosion induced by contouring failure. - Soil \& Tillage Research 136: 1-8.

[14] Liu, Y. S., Guo, Y. J., Li, Y. R., Li, Y. H. (2015): GIS-based effect assessment of soil erosion before and after gully land consolidation: a case study of Wangjiagou project region, Loess Plateau. - Chinese Geographical Science 25(2): 137-146.

[15] Lufafa, A., Tenywa, M. M., Isabirye, M. (2002): Prediction of soil erosion in a Lake Victoria Basin catchment using a GIS-based Universal Soil Loss model. - Agricultural Systems 176(3): 883-894.

[16] Montgomery, D. R. (2007): Soil erosion and agricultural sustainability. - Proceedings of the National Academy of Sciences 104(33): 13268-13272.

[17] Moore, I. D., Wilson, J. P. (1992): Length-slope factors for the revised universal soil loss equation: simplified method of estimation. - Journal of Soil and Water Conservation 47(5): 423-428.

[18] Renard, K. G., Foster, G. R., Weesies, G. (1991): ARUSLE: revised universal soil loss equation. - Journal of Soil and Water Conservation 46(1): 30-33.

[19] Renard, K. G., Foster, G. R., Weesies, G. A. (1997): Predicting Rainfall Erosion by Water: a Guide to Conservation Planning with the Revised Universal Soil Loess Equation (RUSLE). - USDA Agricultural Handbook, Washington, DC, pp. 101-143.

[20] Sharpley, A. N., Williams, J. R. (1990): EPIC-erosion/productivity impact calculator: 1. model documentation. - Technical Bulletin-United States Department of Agriculture 4(4): 206-207.

[21] Sun, W. Y., Shao, Q. Q., Liu, J. Y. (2013): Soil erosion and its response to changes of precipitation and vegetation cover on the Loess Plateau. - Journal of Geographical Sciences 23(6): 1091-1106.

[22] Wang, B., Zhang, G. H., Shi, Y. Y., Zhang, X. C. (2014b): Soil detachment by overland flow under different vegetation restoration models in the Loess Plateau of China. Catena 116: 51-59.

[23] Wang, T., Yang, Q., Yu, D. X. (2014c): Analysis of extreme precipitation in loess plateau area of northern Shaanxi province. - Yunnan Geographic Environment Research 26(4): 7-14 (in Chinese).

[24] Wang, T., Yu, D. X., Yang, Q. (2014d): Characteristics of spatial-temporal change of precipitation in loess plateau area of northern Shaanxi. - Journal of Water Resources \& Water Engineering 25(6): 24-29 (in Chinese). 
[25] Wang, Y. F., Chen, L. D., Fu, B. J., Lyu, Y. H. (2014a): Check dam sediments: an important indicator of the effects of environmental changes on soil in the Loess Plateau in China. - Environmental Monitoring and Assessment 186(7): 4275-4287.

[26] Xie, B. N., Jia, X. X., Qin, Z. F., Shen, J., Chang, Q. R. (2016): Vegetation dynamics and climate change on the Loess Plateau, China: 1982-2011. - Regional Environmental Change 16(6): 1583-1594.

[27] Xie, Y., Liu, B. Y., Zhang, W. B. (2000): Study on standard of erosive rainfall. - Journal of Soil and Water Conservation 14(4): 6-11 (in Chinese)

[28] Xin, Z. B., Qin, Y. B., Yu, X. X. (2016): Spatial variability in soil organic carbon and its influencing factors in a hilly watershed of the Loess Plateau, China. - Catena 137: 660669.

[29] Zhang, L., Bai, K. Z., Wang, M. J., Karthikeyan, R. (2016): Basin-scale spatial soil erosion variability: Pingshuo opencast mine site in Shanxi Province, Loess Plateau of China. - Natural Hazards 80(2): 1213-1230.

[30] Zhang, W. B., Fu, J. S. (2003): Rainfall erosivity estimation under different rainfall modulus. - Resources Science 25(1): 35-41 (in Chinese).

[31] Zhang, W. B., Xie, Y., Liu, B. Y. (2002): Rainfall erosivity estimation using daily rainfall modulus. - Scientia Geographica Sinica 22(6): 705-711 (in Chinese).

[32] Zhao, M. Y., Zhao, W. W., Qiu, Y., Feng, Q., Zhong, L. N. (2014): Scale effect analysis of the influence of land-use types and environmental factors on soil nutrients: a case study in loess areas of northern Shaanxi, China. - Fresenius Environmental Bulletin 23(3): 787-794.

[33] Zhao, T. Y., Yang, M. Y., Walling, D. E., Zhang, F. B., Zhang, J. Q. (2017): Using check dam deposits to investigate recent changes in sediment yield in the Loess Plateau, China. - Global and Planetary Change 152: 88-98.

[34] Zhu, H. H., Wu, J. S., Guo, S. L., Huang, D. Y., Zhu, Q. H., Ge, T. D., Lei, T. W. (2014): Land use and topographic position soil organic $\mathrm{C}$ and $\mathrm{N}$ accumulation in eroded hilly watershed of the Loess Plateau. - Catena 120: 64-72. 